\title{
Inquérito soro-epidemiológico sobre neosporose bovina no norte do estado de Mato Grosso, Brasil
}

\author{
Seroepidemiological inquiry on bovine neosporosis in northern \\ Mato Grosso state, Brazil
}

\author{
Riciely Vanessa Justo ${ }^{1 *}$; Janaina Bacon $\mathrm{Manfio}^{2}$; Juliana Arena Galhardo \\ João Luis Garcia ${ }^{4}$; Artur Kanadani Campos ${ }^{5}$
}

\section{Resumo}

Pesquisou-se a ocorrência de anticorpos anti-Neospora caninum, através da reação de imunofluorescência indireta, em amostras de soro de 205 fêmeas bovinas (Bos taurus indicus) da raça Nelore, pura de origem, com idade igual ou superior a 24 meses, criadas em propriedades rurais nos municípios de Sinop, Itaúba, Colíder, Carlinda e Guarantã do Norte. Aplicou-se ainda questionário epidemiológico aos funcionários responsáveis pelos animais durante o período de 2010-2012. A região estudada revelou condições epidemiológicas favoráveis para a ocorrência da neosporose bovina, com 37,56\% de animais soropositivos para anticorpos anti- $N$. caninum. Sinop (70\%) e Carlinda $(50 \%)$ apresentaram uma frequência de animais soropositivos estatisticamente, igual ao percentual médio observado em outras cidades $(26,67 \%)$ por outros trabalhos no Brasil. Ao confrontar o status sorológico dos animais com as variáveis do questionário, constatou-se associação $(\mathrm{p}<0,01)$ entre soropositividade das fêmeas bovinas e as fontes naturais de água para beber, a ocorrência de aborto e a repetição de cio. Entretanto, não houve associação estatística entre as fêmeas bovinas soropositivas e a ocorrência de mortes neonatais $(\mathrm{p}=$ $0,075)$, natimortos $(\mathrm{p}=0,02)$, presença de cães domésticos $(\mathrm{p}=0,9)$ e a oferta de vísceras cruas aos cães ( $\mathrm{p}=0,93)$. Além da ocorrência de $N$. caninum, ficou evidenciada entre os entrevistados desinformação sobre a neosporose bovina e seu controle. Este primeiro estudo revela a necessidade de pesquisas que retratem, de forma mais abrangente, a epidemiologia da neosporose bovina na região norte do Mato Grosso.

Palavras-chave: Neospora caninum, reação de imunofluorescência indireta, epidemiologia

\begin{abstract}
This work involved the study of anti-Neospora caninum antibodies by indirect immunofluorescence assay in serum samples of 205 cows (Bos taurus indicus) Nellore, pure origin, aged over 24 months, reared on farms in the municipalities of Sinop, Itaúba, Colíder, Carlinda and Guarantã do Norte, Mato Grosso state, Brazil. An epidemiological evaluation through an interview with employees responsible for taking care of the animals during the period of 2010-2012. The studied area revealed epidemiological conditions favorable for the occurrence of bovine neosporosis, with $37.56 \%$ seropositive animals for anti- $N$. caninum. Sinop (70\%) and Carlinda (50\%) showed a frequency of seropositive animals was statistically equal to that observed (26.67\%) in other studies for other cities in Brazil. By confronting

\footnotetext{
${ }^{1}$ Discente de Mestrado, Universidade Federal de Mato Grosso, UFMT, Sinop, MT. E-mail: ricielyjusto@ibest.com.br

${ }^{2}$ Graduada de Medicina Veterinária, UFMT, Sinop, MT. E-mail: janaina_manfio@hotmail.com

${ }^{3}$ Prof $^{a}$ da Universidade Federal do Mato Grosso do Sul, UFMS, Campo Grande, MS. E-mail: jugalhardo@gmail.com

${ }^{4}$ Prof. da Universidade Estadual de Londrina, UEL, Londrina, PR. E-mail: jlgarcia@uel.br

${ }^{5}$ Prof. da UFMT, Sinop, MT. E-mail: arturkanadani@gmail.com

* Autor para correspondência
} 
the serological status of the animals with variables of questionnaire, there was association $(p<0.01)$ between seropositivity of cows and the natural sources of drinking water, the incidence of abortion and repeating estrus. However, there was no statistical association between seropositive cows and the occurrence of neonatal deaths $(p=0.075)$, stillbirths $(p=0.02)$, presence of domestic dogs $(p=0.9)$ and the habit of giving raw offal to dogs $(\mathrm{p}=0.93)$. Besides the occurrence of $N$. caninum, it was evidenced misinformation about bovine neosporosis and its control among interviewed people. This first study shows the need for further research on the epidemiology of bovine neosporosis in northern Mato Grosso state.

Key words: Neospora caninum, indirect immunofluorescence assay, epidemiology

Atualmente, Neospora caninum é considerado o principal agente causador de aborto em fêmeas bovinas, visto que os bovinos são os hospedeiros mais susceptíveis (PIAGENTINI et al., 2012). As fêmeas bovinas podem se infectar ao ingerir pastagem ou água contaminadas por oocistos esporulados de $N$. caninum oriundos de fezes de canídeos que ingeriram músculos ou vísceras contendo cistos teciduais de $N$. caninum (ANDREOTTI, 2001).

Uma novilha infectada por $N$. caninum normalmente sofre aborto no terço médio da primeira gestação, enquanto nas próximas gestações ela transmite o agente ao feto pela placenta sem manifestações clínicas (ANDERSON; ANDRIANARIVO; CONRAD, 2000). Sendo assim, a principal forma de transmissão é a transplacentária, pois resulta no nascimento de bezerros normais com infecção latente que é mantida e, consequentemente, passada para os fetos das futuras gerações (BUXTON; MCALLISTER; DUBEY, 2002).

Devido ao caráter subclínico, estima-se que no Brasil, os prejuízos decorrentes da neosporose bovina sejam superiores aos gerados por leptospirose e brucelose, que também são enfermidades abortivas (VIANNA et al., 2008). O diagnóstico laboratorial da neosporose é possível através da pesquisa de anticorpos anti-N. caninum e a técnica sorológica de referência tem sido a reação de imufluorescência indireta (RIFI), pois apresenta alta sensibilidade e especificidade (MELO et al., 2006).

Além do diagnóstico sorológico, é interessante determinar o perfil epidemiológico da neosporose em diferentes locais do Brasil, pois $N$. caninum apresenta ampla distribuição em muitas regiões brasileiras e os estudos epidemiológicos sobre neosporose são incipientes (TEIXEIRA et al., 2010).

Este trabalho foi conduzido em virtude da ausência de dados epidemiológicos da neosporose bovina na região norte do estado de Mato Grosso com o objetivo de realizar um inquérito soroepidemiológico, determinando-se a ocorrência da infeção por $N$. caninum em fêmeas bovinas e identificando-se fatores de risco associados à doença nas propriedades de origem desses animais.

Foram coletadas amostras de sangue de 205 fêmeas bovinas (Bos taurus indicus) da raça Nelore, puro de origem (PO), com idade igual ou superior a 24 meses, provenientes de cinco rebanhos, um de cada município, destinados à cria e recria, pertencentes às cidades de Sinop (latitude $11^{\circ} 51^{\text {, }}$ 51 " S longitude $55^{\circ} 30^{\prime} 09^{\prime}$ W), Itaúba (latitude $11^{\circ} 03$ ' 42" S longitude $55^{\circ} 16$ ' $35^{\prime \prime} \mathrm{W}$ ), Colíder (latitude $10^{\circ} 49^{\prime} 04^{\prime \prime} \mathrm{S}$ longitude $55^{\circ} 27^{\prime} 03^{\prime \prime} \mathrm{W}$ ),

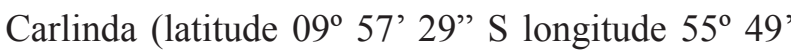
$\left.56^{\prime \prime} \mathrm{W}\right)$ e Guarantã do Norte (latitude $09^{\circ} 47^{\prime} 15^{\prime \prime}$ S longitude $54^{\circ} 54^{\prime} 36^{\prime \prime} \mathrm{W}$ ), localizadas na região norte do estado de Mato Grosso.

Para a amostragem, utilizou-se um nível de confiança de $95 \%$, sensibilidade do teste de $90 \%$ e prevalência esperada de $25 \%$. O cálculo foi feito em função da totalidade de fêmeas, com idade igual ou superior a 24 meses, existentes na propriedade e foi empregada a amostragem aleatória sistemática para as coletas de sangue. Foram coletados 5,0 ml 
de sangue de cada animal através da punção da veia coccígea com agulha hipodérmica descartável $40 \times 12$ em tubo de ensaio sem anticoagulante. Cada amostra foi identificada com o número da propriedade e acondicionada em caixa isotérmica contendo gelo terapêutico.

Após as coletas, aplicou-se um questionário epidemiológico, com questões qualitativas e quantitativas, aos funcionários responsáveis pelo manejo dos animais a fim de identificar fatores de risco entre os anos de 2010-2012: (A) acesso a fontes naturais de água; (B) histórico de aborto; (C) repetição de cio; (D) ocorrência de natimortos; (E) ocorrência de morte neonatal; (F) presença de cães soltos e (G) oferta de vísceras cruas aos cães.

As amostras foram enviadas ao Laboratório de Parasitologia Veterinária e Doenças Parasitárias da Universidade Federal de Mato Grosso em Sinop, refrigeradas e processadas dentro de um prazo máximo de 24 horas após a coleta. O processamento compreendeu a centrifugação na velocidade de 2.400 RPM durante cinco minutos para a armazenagem de $1 \mathrm{ml}$ de soro de cada amostra em microtubos plásticos estéreis. As alíquotas de soro foram identificadas, congeladas e enviadas ao Laboratório de Protozoologia da Universidade Estadual de Londrina (UEL) para a pesquisa de anticorpos IgG anti-N. canimum através da RIFI.

O exame das amostras de soro para a presença de anticorpos séricos anti- $N$. caninum foi realizado pela reação de imunofluorescência indireta segundo Conrad et al. (1993) com modificações, sendo as amostras de soro diluídas a 1:50 e todos os soros com reação ao título 50 considerados positivos.

Com base na frequência de bovinos soropositivos (555/2.253) observada em outros trabalhos (RAGOZO et al., 2003; SARTOR et al., 2003; MELO et al., 2006) adotou-se uma frequência esperada de 24,63\% soropositivos para a amostra total e para cada cidade. Já a frequência esperada para soropositivos em relação aos fatores de risco foi obtida a partir de uma tabela de contingência. Os dados foram testados pelo Qui-quadrado, ao nível de $1 \%$ de significância, com uso do programa Statistical Analysis System (SAS, versão 9.0).

As cinco propriedades apresentaram fêmeas soropositivas para anticorpos anti-N. caninum e houve diferença significativa entre a frequência observada $(37,56 \%)$ e a esperada $(24,63 \%)$ para a amostra total, sendo que a observada se mostrou mais alta que a esperada (Tabela 1). Entretanto, ao avaliar os resultados obtidos com os esperados para cada cidade, os desvios mostraram-se não significativos para Sinop (70\%) e Carlinda (50\%). Isso revela que as fêmeas bovinas desses municípios apresentaram uma frequência de anticorpos anti- $N$. caninum estatisticamente igual à média percentual de $24,63 \%$ obtida nos trabalhos de Melo et al. (2006), Ragozo et al. (2003) e Sartor et al. (2003) que avaliaram respectivamente, bovinos de corte e leite de Goiânia e Anápolis e vacas leiteiras do Mato Grosso do Sul, Minas Gerais, Paraná, Rio de Janeiro, Rio Grande do Sul e São Paulo. No entanto, Melo et al. (2006) pesquisaram títulos $\geq 1: 250$, Ragozo et al. (2003) 1:25 e Sartor et al. (2003) 1:200, enquanto neste trabalho utilizou-se a diluição 1:50. 
Tabela 1. Ocorrência de anticorpos anti- $N$. caninum em fêmeas bovinas Nelore, puro de origem, na região norte do Mato Grosso, pela reação de imunofluorescência indireta (títulos $=1: 50$ ). A análise da frequência observada em relação à esperada pelo teste do Qui-quadrado $(\alpha=0,01)$ está apresentada para cada propriedade.

\begin{tabular}{|c|c|c|c|c|c|c|}
\hline \multirow{2}{*}{ Cidade } & \multirow{2}{*}{ Amostra } & \multicolumn{2}{|c|}{ Sorologia } & \multirow{2}{*}{$\begin{array}{l}\text { Frequência } \\
\text { Observada }\end{array}$} & \multirow{2}{*}{$\chi^{2}$} & \multirow{2}{*}{$P$} \\
\hline & & + & - & & & \\
\hline Sinop & 60 & 42 & 18 & $70 \%$ & $0,93 *$ & 0,33 \\
\hline Itaúba & 30 & 8 & 22 & $26,67 \%$ & 38,33 & $<0,01$ \\
\hline Colíder & 48 & 10 & 38 & $20,83 \%$ & 76,91 & $<0,01$ \\
\hline Carlinda & 22 & 11 & 11 & $50 \%$ & 7,63 & 0,06 \\
\hline Guarantã do Norte & 45 & 6 & 39 & $13,33 \%$ & 93,29 & $<0,01$ \\
\hline Total & 205 & 77 & 128 & $37,56 \%$ & 157,86 & $<0,01$ \\
\hline
\end{tabular}

$\chi^{2}=$ Qui-quadrado calculado.

$* \mathrm{H}_{0}=$ Proporção entre $24,63 \%$ positivos e $75,37 \%$ negativos.

$\mathrm{P}=$ Probabilidade.

Fonte: Elaboração dos autores.

Através do questionário, observou-sequeemtodas as propriedades havia oferta de água proveniente de fontes naturais, como rios ou riachos configurando fator de risco para neosporose e contribuindo para a epidemiologia da doença. Da mesma forma, todas as propriedades apresentaram uma taxa de $2-10 \%$ de aborto com $80 \%$ dos casos no terço médio da gestação e uma taxa de 10-15\% de repetição de cio, sugestivas de alterações reprodutivas de origem infecciosa. Sendo assim, tanto a procedência da água de beber quanto a ocorrência de aborto e repetição de cio nas propriedades apresentaram associação $(p<0,01)$ com o status soropositivo dos animais. Segundo Hein et al. (2012) os animais apresentam risco 7,21 (IC 95\%, 3,65-14,32) vezes maior de apresentar anticorpos anti- $N$. caninum se apresentarem histórico de abortamento. Esse fato torna a associação entre histórico de aborto e soropositividade para N. caninum bastante relevante e frequente em bovinos.

Apesar de haver histórico, não houve associação estatística entre as fêmeas bovinas soropositivas e a ocorrência de mortes neonatais $(\mathrm{p}=0,075)$ e natimortos $(\mathrm{p}=0,02)$ nos anos de 2010 a 2012, indicando eventual caráter subclínico da neosporose e sua principal forma de transmissão que pode culminar no nascimento de bezerros clinicamente, hígidos, porém infectados por $N$. caninum
(BUXTON; MCALLISTER; DUBEY, 2002).

Em todas as propriedades ficou evidenciada desinformação sobre a enfermidade, seu diagnóstico e controle. A infecção pelo agente tem sido subdiagnosticada na região norte do Mato Grosso conforme informações obtidas pelo questionário, sendo constatado que, apesar de $40 \%$ das propriedades empregarem o diagnóstico laboratorial na tentativa de descobrir a causa dos abortos, $50 \%$ desses diagnósticos eram realizados para brucelose enquanto os outros 50\% para brucelose, rinotraqueíte infecciosa bovina (IBR) e diarreia viral bovina (BVD). Entre 2010 e 2012, todos esses testes apresentaram resultados negativos nas propriedades avaliadas.

Ressalta-se ainda a possibilidade de haver infecção simultânea por $N$. caninum e Toxoplasma gondii, conforme verificaram Costa et al. (2001) em 54 vacas que apresentaram títulos de anticorpos para ambos os coccídios. Portanto, não basta incluir a pesquisa sorológica para anticorpos anti- $N$. caninum sem o diagnóstico diferencial para $T$. gondii, devido à possibilidade de reações cruzadas como relatado por Dubey e Lindsay (1996). Também devido ao caráter subclínico da neosporose, é importante acrescentar a RIFI para a detecção de anticorpos anti- $N$. caninum na rotina das fazendas, pois segundo Andreotti et al. (2010) 
existe uma correlação positiva entre a presença de anticorpos anti- $N$. caninum e a não concepção. Sendo assim, as fêmeas soropositivas podem ser identificadas e descartadas a fim de minimizar os prejuízos decorrentes de problemas reprodutivos.

Todas as fêmeas bovinas eram criadas em sistema de pastejo direto e ocasionalmente, conviviam com cães domésticos. Cada propriedade possuía no mínimo dois cães para trabalho ou guarda e companhia. Nas propriedades onde os cães ficavam parcial ou totalmente soltos, foi observado que tinham livre acesso às fontes de água e pastagens utilizadas pelos bovinos, entretanto, não houve associação $(\mathrm{p}=0,9)$ entre a presença destes e a ocorrência de fêmeas bovinas soropositivas. Além disso, por meio do questionário, foi verificada a oferta de vísceras cruas aos cães após a matança de bovinos e, em alguns casos, era permitido que os cães comessem restos fetais e placentas, mas sem associação $(p=0,93)$ com a soropositividade das fêmeas bovinas. Apesar da ausência desta associação para os cães domésticos, é possível que haja participação de canídeos selvagens no ciclo natural da doença (ANDREOTTI, 2001).

A existência de casos alóctones dentre os animais avaliados também é possível uma vez que duas propriedades possuíam animais recentemente adquiridos de outras cidades. Essas propriedades haviam adquirido conjuntamente, cerca de 650 fêmeas bovinas, entre vacas e novilhas, provenientes de São Paulo, Goiás, Pará, Minas Gerais e de outras regiões do Mato Grosso há menos de um ano antes deste estudo.

Este primeiro estudo indica presença de fêmeas Nelore PO portadoras de anticorpos anti-N. caninum e reflete a importância da neosporose na região norte do Mato Grosso. Também revela que $N$. caninum é uma ameaça ao potencial produtivo do estado que, conforme o Instituto Mato-grossense de Economia Agropecuária (IMEA, 2010) pretende saltar dos atuais 27,2 milhões de cabeças para 33,9 milhões até 2020. É urgente a necessidade de estudos mais abrangentes e implantação de medidas sanitárias que venham prevenir e controlar esta enfermidade. Este primeiro estudo desperta para a necessidade de novas pesquisas sobre a prevalência da neosporose bovina, de forma mais abrangente, na região norte do estado de Mato Grosso.

\section{Referências}

ANDERSON, M. L.; ANDRIANARIVO, A. G.; CONRAD, P. A. Neosporosis in cattle. Animal Reproduction Science, Amsterdan, v. 60-61, p. 417-431, 2000.

ANDREOTTI, R. Neosporose: um possível problema reprodutivo para o rebanho bovino. Campo Grande: Embrapa Gado de Corte, 2001. 14 p. (Documentos; Embrapa Gado de Corte, 104).

ANDREOTTI, R.; BARROS, J. C.; PEREIRA, A. R.; OSHIRO, L. M.; CUNHA, R. C.; FIGUEIREDO NETO, L. F. Association between seropositivity for Neospora caninum and reproductive performance of beef heifers in the Pantanal of Mato Grosso do Sul, Brazil. Revista Brasileira de Parasitologia Veterinária, Rio de Janeiro, v. 19, n. 2, p. 119-123, 2010.

BUXTON, D.; MCALLISTER, M. M.; DUBEY, J. P. The comparative pathogenesis of neosporosis. Trends in Parasitology, Holanda, v. 18, n. 12, p. 544-552, 2002.

CONRAD, P. A.; BARR, B. C.; SVERLOW, K. W.; ANDERSON, M.; DAFT, B.; KINDE, H.; DUBEY, J. P.; MUNSON, L.; ARDANS, A. In vitro isolation and characterization of a Neospora sp. from aborted bovine foetuses. Parasitology, Cambridge, v. 106, n. 3, p. 239249, 1993.

COSTA, G. H. N.; CABRAL, D. D.; VARANDAS, N. P.; SOBRAL, E. A.; BORGES, F. A.; CASTAGNOLLI, K. C. Freqüência de anticorpos anti-Neospora caninum e Toxoplasma gondii em soros de bovinos pertencentes aos estados de São Paulo e de Minas Gerais. Semina: Ciências Agrárias, Londrina, v. 22, n. 1, p. 61-66, 2001.

DUBEY, J. P.; LINDSAY, D. S. A review of Neospora caninum and neosporosis. Veterinary Parasitology, Amsterdam, v. 67, n. 1-2, p. 1-59, 1996.

HEIN, H. E.; MACHADO, G.; MIRANDA, I. C. S.; COSTA, E. F.; PELLEGRINI, D. C. P.; DRIEMEIER, D.; CORBELLINI, L. G. Neosporose bovina: avaliação da transmissão vertical e fração atribuível de aborto em uma população de bovinos no estado do Rio Grande do Sul. Pesquisa Veterinária Brasileira, Porto Alegre, v. 32, n. 5, p. 396-400, 2012. 
INSTITUTO MATO-GROSSENSE DE ECONOMIA AGROPECUÁRIA - IMEA. Projeções para produção agropecuária em Mato Grosso. Cuiabá: Instituto Matogrossense de Economia Agropecuária, 2010. 4 p.

MELO, D. P. G.; SILVA, A. C. da; ORTEGA-MORA, L. M.; BASTOS, S. A.; BOAVANTURA, C. M. Prevalência de anticorpos anti-Neospora caninum em bovinos das microrregiões de Goiânia e Anápolis, Goiás, Brasil. Revista Brasileira de Parasitologia Veterinária, Jaboticabal, v. 3, n. 15, p. 105-109, 2006.

PIAGENTINI, M.; MOYA-ARAUJO, C. F.; PRESTES, N. C.; SARTOR, I. F. Neospora caninum infection dynamics in dairy cattle. Parasitology Research, Berlin, v. 111, n. 2, p. 717-721, 2012.

RAGOZO, A. M. A. R.; PAUlA, V. S. O.; SOUZA, S. L. P.; BERGASMASCHI, D. P.; GENNARI, S. M. Ocorrência de anticorpos anti-Neospora caninum em soros bovinos procedentes de seis estados brasileiros. Revista Brasileira de Parasitologia Veterinária, Jaboticabal, v. 1, n. 12, p. 33-37, 2003.
SARTOR, I. F.; HASEGAWA, M. Y.; CANAVESSI, A. M. O.; PINCKNEY, R. D. Ocorrência de anticorpos de Neospora caninum em vacas leiteiras avaliadas pelos métodos ELISA e RIFI no município de Avaré, SP. Semina: Ciências Agrárias, Londrina, v. 1, n. 24, p. 3-10, 2003.

TEIXEIRA, W. C.; UZÊDA, R. S.; GONDIM, L. F. P.; SILVA, M. I. S.; PEREIRA, H. M.; ALVES, L. C.; FAUSTINO, M. A. G. Prevalência de anticorpos antiNeospora caninum (Apicomplexa: Sarcocystidae) em bovinos leiteiros de propriedades rurais de três microrregiões no estado do Maranhão. Pesquisa Veterinária Brasileira, Rio de Janeiro, v. 30, n. 9, p. 729734, 2010.

VIANNA, L. C.; SARTOR, I. F.; PITUCO, E. M.; OKUDA, L. H.; CAMARGO, C. N.; KRONKA, S. N. Incidence and transplacental transmission of Neospora caninum in primiparous females from Bos indicus slaughtered in Presidente Prudente, São Paulo, Brazil. Semina: Ciências Agrárias, Londrina, v. 29, n. 2, p. $387-$ 392, 2008. 